Article

\title{
Tin Oxide-Silver Composite Nanomaterial Coating for UV Protection and Its Bactericidal Effect on Escherichia coli (E. coli)
}

Gil Nonato C. Santos ${ }^{1}$ *, Eduardo B. Tibayan ${ }^{1}$, Gwen B. Castillon ${ }^{1}$, Elmer Estacio ${ }^{2}$, Takashi Furuya ${ }^{3}$, Atsushi Iwamae ${ }^{3}$, Kohji Yamamoto ${ }^{3}$ and Masahiko Tani ${ }^{3}$

1 Solid State Physics Laboratory, De La Salle University-Manila, 2401 Taft Ave., Manila 1004, Philippines; E-Mails: sir_ed26@yahoo.com (E.B.T.); gwen.castillon@dlsu.edu.ph (G.B.C.)

2 National Institute of Physics, University of the Philippines, Diliman Quezon City 1101, Philippines; E-Mail: estacio@fir.u-fukui.ac.jp

3 Research Center for Development of Far-Infrared Region, University of Fukui, Fukui 910-8507, Japan; E-Mails: furuya@fir.u-fukui.ac.jp (T.F.); iwamae@fir.u-fukui.ac.jp (A.I.);

kohji@fir.u-fukui.ac.jp (K.Y.); tani@fir.u-fukui.ac.jp (M.T.)

* Author to whom correspondence should be addressed; E-Mail: gil.santos@dlsu.edu.ph; Tel.: +63-2-524-4611 (ext. 450); Fax: +63-2-536-0229.

Received: 4 December 2013; in revised form: 23 April 2014 / Accepted: 29 April 2014 / Published: 6 May 2014

\begin{abstract}
SnO}_{2}-\mathrm{Ag}$ composite nanomaterials of mass ratio 1:4, 2:3, 3:2 and 4:1 were fabricated and tested for toxicity to $E$. coli using the pour-plate technique. The said nanomaterials were mixed with laminating fluid and then coated on glass slides. The intensity of UVA transmitted through the coated glass slides was measured. Results revealed that the 1:4 ratios of $\mathrm{SnO}_{2}-\mathrm{Ag}$ composite nanomaterials have the optimum toxicity to E. coli. Furthermore, the glass slides coated with $\mathrm{SnO}_{2}$ nanomaterial showed the lowest intensity of transmitted UVA.
\end{abstract}

Keywords: horizontal vapor phase growth (HVPG) technique; antimicrobial; UV-property; tin-oxide silver nanocomposite materials; UV-VIS spectrophotometer; FT-IR spectrometer

\section{Introduction}

Glass materials in windows tend to act as good media for the growth and multiplication of microorganisms. The chemical constituents that are absorbed and deposited on glass windows provide 
nutrition to microorganisms; and thereby promote their growth [1]. The growth of microorganisms on the glass materials causes innumerable problems such as stains [2] and unacceptable odor [3] which is detrimental to human health [4]. It is therefore important to develop glass or glass coating materials with antimicrobial properties to protect the health of the populace.

On the other hand, it is known that ultraviolet radiation in the wavelength range of 280 to $320 \mathrm{~nm}$, which is referred to as UVB, is harmful to the human skin. It causes sunburn, stains, or even skin cancer [5]. UVA, of wavelength range of 320-400 $\mathrm{nm}$ is harmful as well, causing skin aging and wrinkling (photoaging). It also causes photocarcinogenesis due to its ability to penetrate the dermal layers, unlike UVB which is absorbed by the epidermis [6]. The science and technology of protecting people against the harmful effects of UV radiation had received increasing interests most especially to countries with tropical climate wherein incidences of heat wave occurs [7]. Tinted glass windows are commonly used in buildings and vehicles to protect people from UV rays. However, the use of tints which are too dark is prohibited by law enforcement agencies since the use of such tints have been increasingly used in criminal activities [8-11]. It is therefore important to develop glass that is not tinted but is able to allow enough visible light to pass through. In this study, tin oxide-silver $\left(\mathrm{SnO}_{2}-\mathrm{Ag}\right)$ composite nanomaterials were fabricated. Toxicity of the nanomaterials to E. coli bacteria was tested. The nanomaterials were mixed with laminating fluid. The mixtures were then coated on glass slides and allowed to dry. The ability of the coated glass slides to block UVA was monitored.

\section{Experimental Section}

\subsection{Preparation of Nanoparticles}

The raw materials used were Sigma Aldrich (St. Louis, MO, USA) Ag powder with 99.99\% purity and $<45 \mu \mathrm{m}$ grain size and Merck $\mathrm{SnO}_{2}$ powder of $99 \%$ purity with $<5 \mu \mathrm{m}$ grain size. The horizontal vapor phase crystal growth technique (HVPG) was used in the fabrication of $\mathrm{SnO}_{2}$ nanomaterials, $\mathrm{Ag}$ nanomaterials, and $\mathrm{SnO}_{2}-\mathrm{Ag}$ composite nanomaterials. In the said technique, $35 \mathrm{mg}$ of $\mathrm{SnO}_{2}, \mathrm{Ag}$, and mixtures of $\mathrm{SnO}_{2}$ with Ag powders at 1:4, 2:3, 3:2, and 4:1 mass ratio were placed into an ultrasonically clean closed-end quartz tubes with inner diameter of $8.5 \mathrm{~mm}$, outer diameter of $11 \mathrm{~mm}$, and length of $220 \mathrm{~mm}$. The tube was evacuated using the Thermionics High Vacuum System with a vacuum pressure of $10^{-6}$ Torr which was sealed on the other end using by an Oxy-LPG gas mixture blow torch. The sealed quartz tubes were then placed in a Thermolyne horizontal tube furnace and were baked at a temperature of $800{ }^{\circ} \mathrm{C}$ with growth time of $6 \mathrm{~h}$ and ramp time of $80 \mathrm{~min}$.

\subsection{Characterization of Nanoparticles}

The surface and elemental analysis of the $\mathrm{SnO}_{2}$ nanomaterials, $\mathrm{Ag}$ nanomaterials, and $\mathrm{SnO}_{2}-\mathrm{Ag}$ composite nanomaterials were carried out using JEOL SEM 5310 scanning electron microscope and Oxford EDX System, respectively. The pour-plate technique was then utilized to confirm the antimicrobial properties of the nanomaterials. In the said technique, E. coli bacterial solutions of $10^{-4}$ dilution factor were prepared through serial dilution from 0.5 Macfarland based standard solution. $2 \mathrm{~mm}$ of the said solutions were then poured into 6 opened quartz tubes. One quartz tube contained $\mathrm{Ag}$ nanomaterials, one quartz tube contained $\mathrm{SnO}_{2}$ nanomaterials, while the other four tubes contained 
$\mathrm{SnO}_{2}$-Ag nanomaterials of varying ratio of $1: 4,2: 3,3: 2$, and 4:1. Two additional quartz tubes were used, one containing $\mathrm{Ag}$ powder and another containing $\mathrm{SnO}_{2}$ powder, in order to compare the effect on the bacterial activity of the bulk powders and nanomaterials. The quartz tubes containing the bacterial solutions were then shaken. One hundred microliters of the bacterial solution from each quartz tube was poured in separate sterile petri dishes. A $9 \mathrm{~mL}$ sterile and cold nutrient agar medium was then poured into each petri dish containing the bacterial solutions. The contents were thoroughly mixed and allowed to solidify. The dishes were then incubated at $35^{\circ} \mathrm{C}$ for $24 \mathrm{~h}$ before comparing the colonies grown on each petri dish.

\subsection{Characterization of Coatings}

In performing the UVA test, $1 \mathrm{mg}$ of $\mathrm{Ag}$ nanomaterials, $\mathrm{SnO}_{2}$ nanomaterials, $\mathrm{SnO}_{2}$ - $\mathrm{Ag}$ composite nanomaterials, $\mathrm{Ag}$ powder, and $\mathrm{SnO}_{2}$ powder were each mixed with $3 \mathrm{~mL}$ of laminating fluid. Clean glass substrates were then coated with the nanomaterials-laminating fluid mixtures via the drip method. The UV optical properties of the coated glass slides were examined using the PASCO UVA light sensor in conjunction with an OMNI PAR 38 Flood $120 \mathrm{~W}$ lamp light source.

\section{Results and Discussion}

\subsection{Surface Morphology and Elemental Composition of the Nanomaterials}

Figure 1 shows the SEM images of (a) silver, (b) tin oxide, and (c,d) silver tin oxide nanomaterials grown at $800^{\circ} \mathrm{C}$ with growth time of $6 \mathrm{~h}$. The micrographs revealed the presence of nanoparticles, wires, and cotton-like structures grown in random directions.

Table 1 exhibits the atomic and elemental composition of the $\mathrm{SnO}_{2}-\mathrm{Ag}$ composite nanomaterials at 1:4 ratio, $2: 3$ ratio, $3: 2$ ratio and $4: 1$ ratio. The resulting elemental and atomic composition confirmed the presence of $\mathrm{Ag}, \mathrm{Sn}$, and $\mathrm{O}$ in the composite nanomaterials.

Figure 1. SEM images of nanomaterials (a) silver; (b) tin oxide; and (c,d) silver tin oxide.

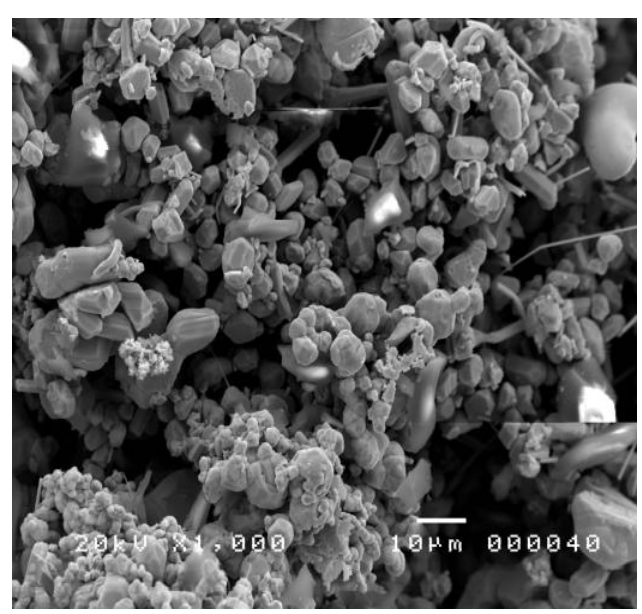

(a)

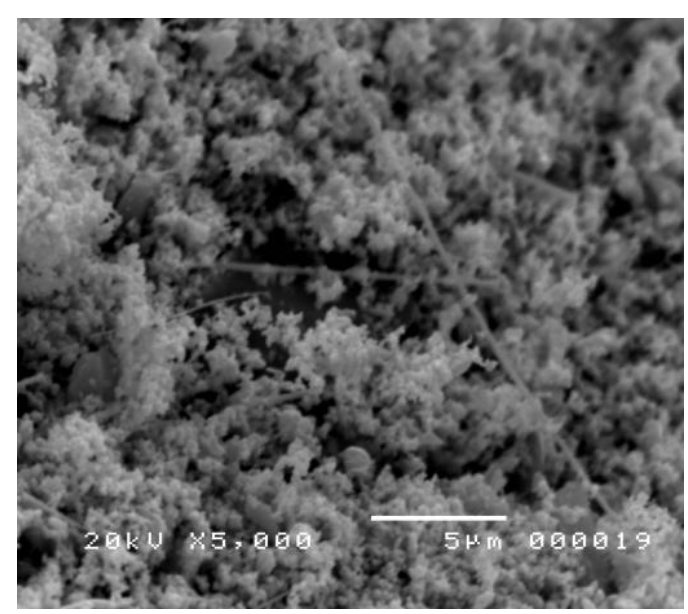

(b) 
Figure 1. Cont.

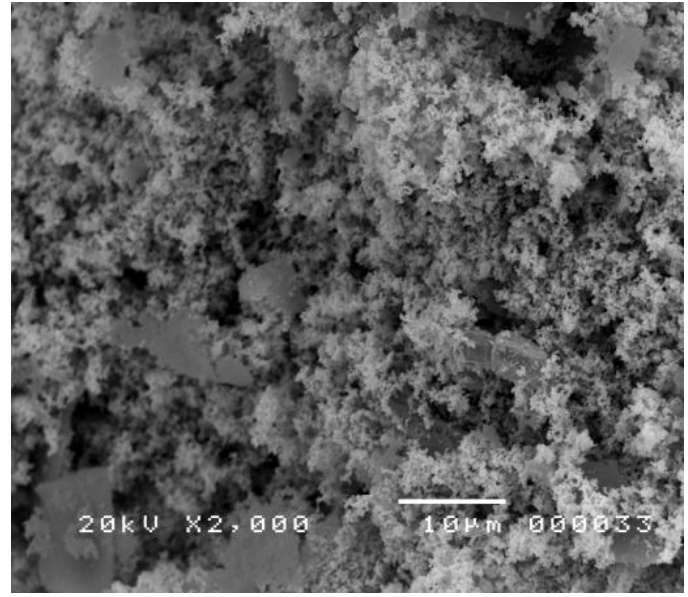

(c)

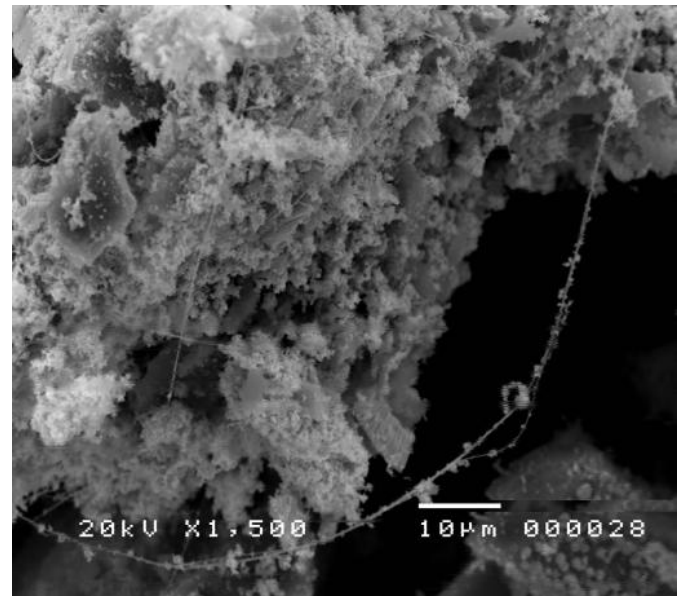

(d)

Table 1. Energy-dispersive X-ray spectroscopy (EDX) analysis of $\mathrm{SnO}_{2}-\mathrm{Ag}$ nanomaterials at 1:4 mixture, 2:3 mixture, 3:2 mixture, and 4:1 mixture.

\begin{tabular}{cccc}
\hline Ratio & Element & Elem\% & Atom\% \\
\hline \multirow{3}{*}{$1: 4$} & $\mathrm{O}$ & 24.75 & 69.70 \\
& $\mathrm{Ag}$ & 45.84 & 19.14 \\
& $\mathrm{Sn}$ & 29.71 & 11.16 \\
& $\mathrm{Total}$ & 100.00 & 100.00 \\
\hline \multirow{3}{*}{$2: 3$} & $\mathrm{O}$ & 34.00 & 78.94 \\
& $\mathrm{Ag}$ & 20.27 & 4.37 \\
& $\mathrm{Sn}$ & 45.73 & 16.69 \\
& $\mathrm{Total}$ & 100.00 & 100.00 \\
\hline \multirow{3}{*}{$3: 2$} & $\mathrm{O}$ & 36.30 & 84.75 \\
& $\mathrm{Ag}$ & 10.38 & 3.18 \\
& $\mathrm{Sn}$ & 53.32 & 12.06 \\
& $\mathrm{Total}$ & 100.00 & 100.00 \\
\hline \multirow{3}{*}{$4: 1$} & $\mathrm{O}$ & 20.83 & 66.02 \\
& $\mathrm{Ag}$ & 3.59 & 1.69 \\
& $\mathrm{Sn}$ & 75.58 & 32.29 \\
& $\mathrm{Total}$ & 100.00 & 100.00 \\
\hline
\end{tabular}

\subsection{Antimicrobial Activity}

The two controls used in the study are shown in Figure 2a,b. Figure 2a shows an agar plate without any bacterial colony. Instead of adding bacterial solution to the sterile petri dish, only distilled water was poured into it. On the other hand, Figure $2 b$ shows an agar plate with several bacterial colonies seen as tiny white spots.

It can be seen in Figure 3 that there are fewer CFUs on the agar plate with Ag nanomaterials compared to the agar plate with the bulk Ag powder. Likewise, there are fewer CFUs on the agar plate with the $\mathrm{SnO}_{2}$ nanomaterials than on the agar plate with bulk $\mathrm{SnO}_{2}$ powder. This is consistent with the 
finding of Espulgar and Santos [12] that the antimicrobial property of bulk material was not only carried over but was enhanced by its nanomaterial counterpart.

Figure 4 shows that there are fewer CFUs for the agar plate with the 1:4 ratio of $\mathrm{SnO}_{2}-\mathrm{Ag}$ composite nanomaterials as compared to the 2:3, 3:2, and 4:1 ratio of $\mathrm{SnO}_{2}-\mathrm{Ag}$ composite nanomaterials.

Figure 2. Agar plates used as control for comparison: (a) Agar plate without bacteria; (b) Agar plate with bacteria.

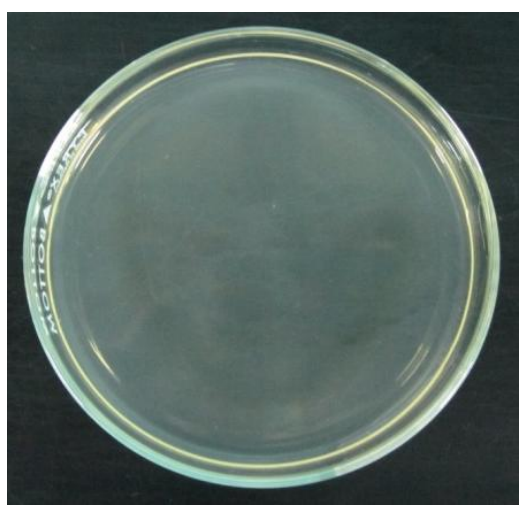

(a)

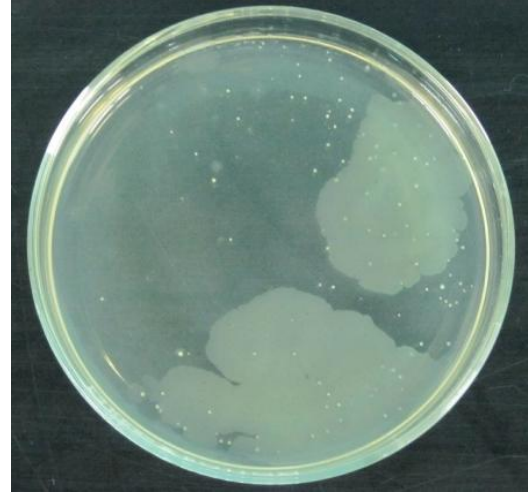

(b)

Figure 3. Comparison on colony forming units (CFU) between (a,c) powder and $(\mathbf{b}, \mathbf{d})$ nanomaterial on $(\mathbf{a}, \mathbf{b}) \mathrm{Ag}$ and $(\mathbf{c}, \mathbf{d}) \mathrm{SnO}_{2}$.

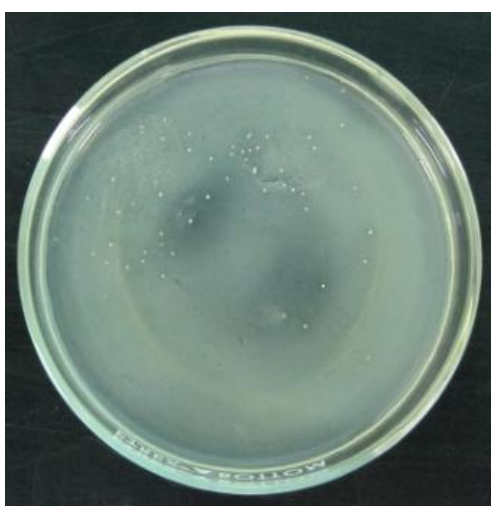

(a)

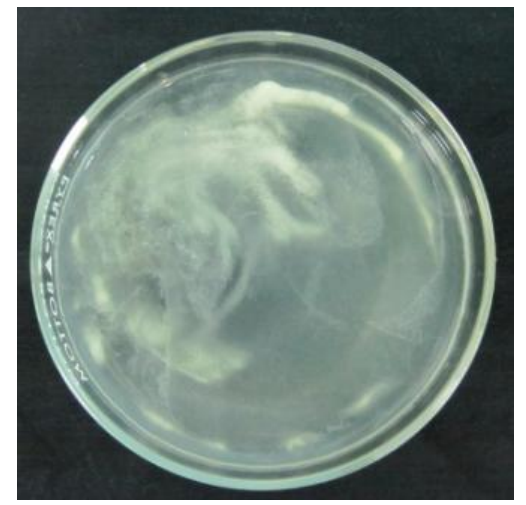

(c)

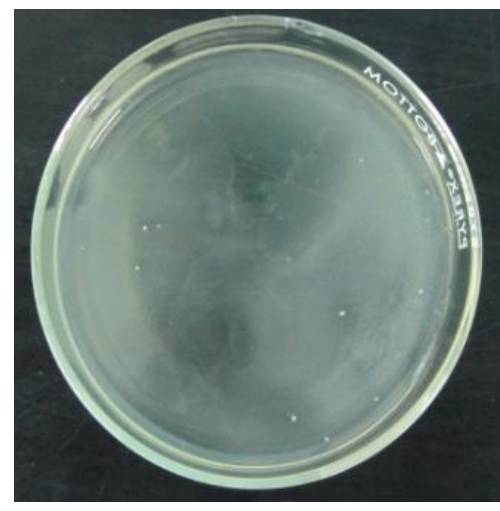

(b)

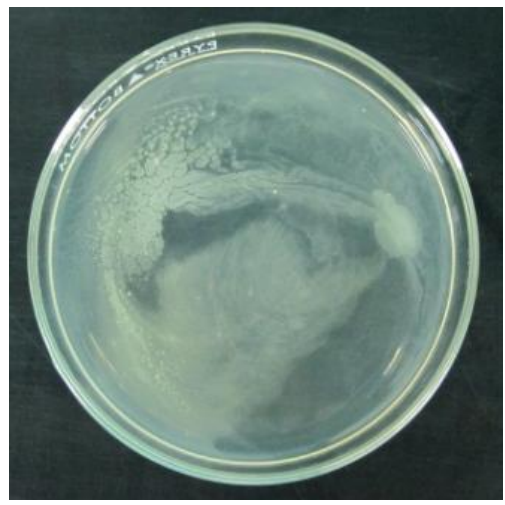

(d) 
Figure 4. Agar plates containing mixtures of bacterial solution and nanomaterials of different ratio: (a) $1: 4 ;$ (b) 2:3; (c) 3:2; (d) 4:1.

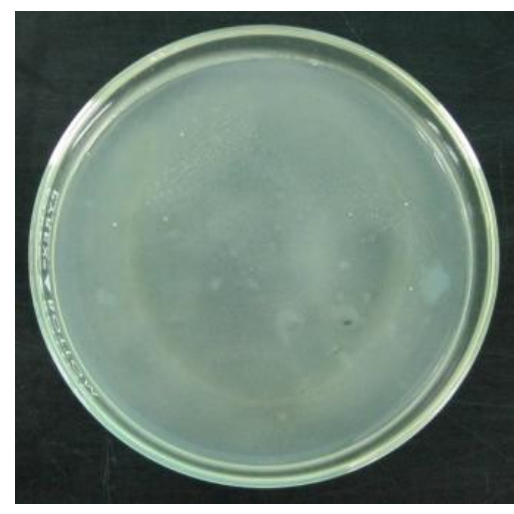

(a)

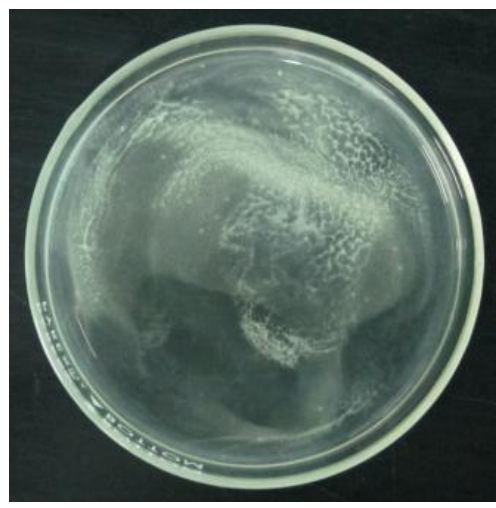

(c)

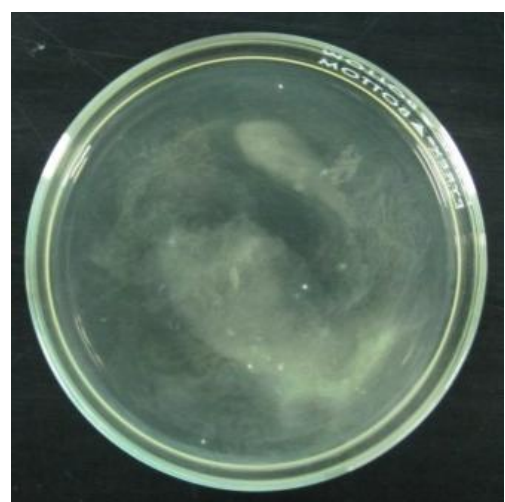

(b)

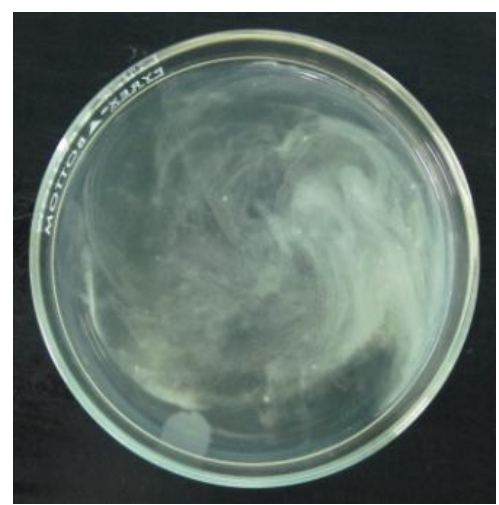

(d)

Table 2 summarizes the result of the antibacterial test where the number of CFU after $24 \mathrm{~h}$ of incubation was shown. It can be seen that $\mathrm{Ag}$ is more toxic to E. coli than $\mathrm{SnO}_{2}$ and that the nanomaterials are more toxic than their bulk form. Also, it can be observed that as the percentage of Silver increases over tin oxide, the CFU number decreases. This is consistent with the observation that $\mathrm{Ag}$ is more toxic to E. coli than $\mathrm{SnO}_{2}$. Moreover, results reveal that the 1:4 ratio of tin oxide and silver composite nanomaterials exhibits the greatest antimicrobial effect among the other ratios and material composition. Such a finding is consistent with previous reports $[13,14]$ that the combination of Ag and a metal oxide may lead to an increase in bactericidal effect.

Table 2. Colony forming units (CFU) vs. material composition.

\begin{tabular}{|c|c|c|}
\hline \multicolumn{2}{|c|}{ Material } & CFU \\
\hline \multicolumn{2}{|c|}{ Ag powder } & 59 \\
\hline \multicolumn{2}{|c|}{ Ag nanomaterial } & 18 \\
\hline \multicolumn{2}{|c|}{$\mathrm{SnO}_{2}$ powder } & 500 \\
\hline \multicolumn{2}{|c|}{$\mathrm{SnO}_{2}$ nanomaterial } & 35 \\
\hline \multirow{4}{*}{$\mathrm{SnO}_{2}-\mathrm{Ag}$ composite } & $1: 4$ ratio & 9 \\
\hline & $2: 3$ ratio & 19 \\
\hline & $3: 2$ ratio & 20 \\
\hline & $4: 1$ ratio & 31 \\
\hline \multicolumn{2}{|c|}{ E. Coli } & 149 \\
\hline
\end{tabular}


The mechanisms of the bactericidal effect of silver and silver nanoparticles (NPs) were discussed in different studies according to literature [15]. A study proposed that silver NPs can be attached to the surface of the cell membrane disturbing the permeability and respiration functions of the cell [4]. Smaller silver NPs having large surface area that are available for interaction would be more bactericidal than the larger silver NPs [16]. Moreover, it is possible that silver NPs will not only interact with the surface of membrane but can also penetrate inside the bacteria [17].

\subsection{UVA Analysis of the Samples}

Before the UVA transmission measurement was obtained, samples were first prepared by mixing $1 \mathrm{mg}$ of $\mathrm{Ag}$ nanomaterials, $\mathrm{SnO}_{2}$ nanomaterials, $\mathrm{SnO}_{2}$ - $\mathrm{Ag}$ composite nanomaterials, $\mathrm{Ag}$ powder, and $\mathrm{SnO}_{2}$ powder with $3 \mathrm{~mL}$ of laminating fluid. Clean glass substrates were then coated with the nanomaterials-laminating fluid mixtures via the drip method. The coated glass slides were air dried and were later exposed to an OMNI PAR 38 Flood $120 \mathrm{~W}$ lamp light source. The relative intensity vs. time graph was obtained using a PASCO UVA light Sensor and was plotted using PASCO's Data Studio real time graph software. The graphs obtained are shown in Figure 5. As can be seen in the figure, the relative intensity was reduced when the glass slide was coated with the laminating fluid mixed with silver and tin oxide bulk powder. The basis for the decrease in intensity is that the material's surface was opaque and blocks UV light. On the other hand, the glass slide coated with the laminating fluid mixed with 4:1 ratio of tin oxide and silver nanomaterials had the least transmission for UVA and was transparent to visible light.

Figure 5. Graph of relative intensity of UVA vs. time graph of tin-oxide, silver, mass ratio of tin oxide silver nanocomposite material, glass slide, and without glass slide.

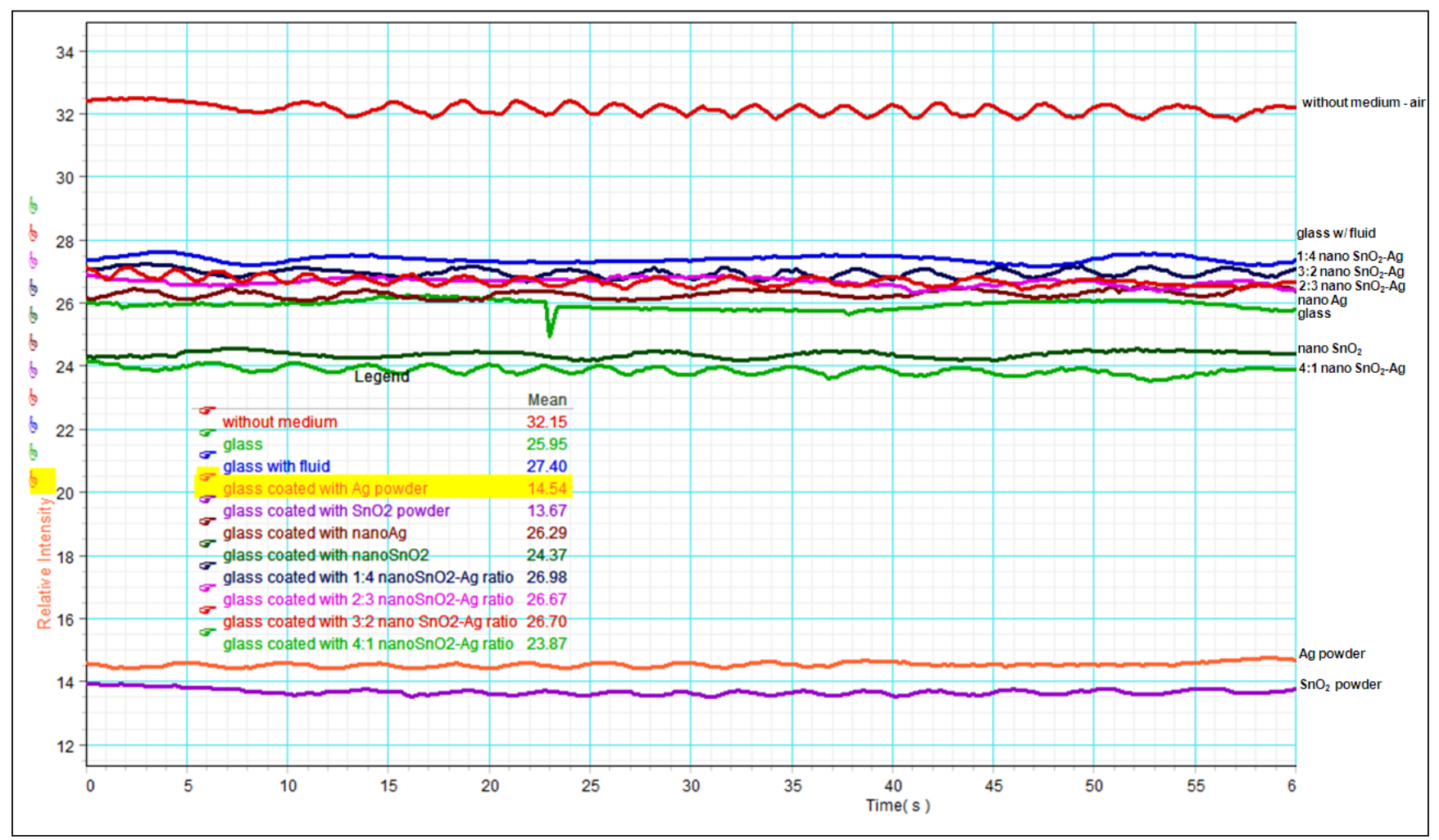




\section{Conclusions}

The HVPG technique was found to be effective in fabricating tin oxide and silver nanomaterials. The antimicrobial test shows that reducing the size of the sample to its nano form increases its toxicity to E. coli bacteria. Moreover, the glass slides coated with the laminating fluid mixed with tin oxide nanomaterial exhibits excellent UV blocking properties.

\section{Acknowledgments}

The researchers would like to thank DOST PCIEERD for the research grant for this project, M. Hangyo and K. Takano for the far infrared to mid-IR FT-IR measurements in their lab at the Institute of Laser Engineering, Osaka University. They also thank N. Miyoshi for his help for the near-IR FT-IR measurements in his lab at the Faculty of Medical Sciences, University of Fukui.

\section{Author Contributions}

Gil Nonato C. Santos is in charge of consolidation of the results and writing of the paper while Eduardo B. Tibayan and Gwen Castillon edited, synthesized and performed the antimicrobial tests. Elmer Estacio edited the paper regarding the optical characterization of the samples while Takashi Furuya, Atsushi Iwamae, and Kohji Yamamoto made the set up and performed the experiment of the samples using the FTIR and UV-VIS equipment. Masahiko Tani analyzed the UV blocking property of the samples.

\section{Conflicts of Interest}

The authors declare no conflict of interest.

\section{References}

1. Skarstad, K.; Steen, H.; Boye, E. Cell cycle parameters of slowly growing Escherichia coli studied by flow cytometry. J. Bacteriol. 1983, 154, 656-662.

2. Métris, A.; George, S.; Peck, M. Distribution of turbidity detection times produced by single cell-generated bacterial populations. J. Microbiol. Methods 2003, 55, 821-827.

3. Edwards, P.R.; Ewing, W.H. Identification of Enterobacteriaceae; Burgess Pub. Co.: Minneapolis, MN, USA, 1972.

4. Poindexter, J.S.; Leadbetter, E.R. Methods and Special Applications in Bacterial Ecology; Plenum Press: New York, NY, USA, 1986; p. 87.

5. Hockberger, P.E. A history of ultraviolet photobiology for humans, animals and microorganisms. Photochem. Photobiol. 2002, 76, 561-579.

6. Damiani, E.; Rosati, L.; Carloni, P.; Greci, L. Changes in ultraviolet absorbance and hence in protective efficacy against lipid peroxidation of organic sunscreens after UVA irradiation. J. Photochem. Photobiol. B Biol. 2006, 82, 204-213.

7. Matsumu, Y.; Ananthaswamy, H.N. Toxic effects of ultraviolet radiation on the skin. Toxicol. Appl. Pharmacol. 2004, 195, 298-308. 
8. Pereira, V. Mangalore: Once Again Cops in Action to Impose Ban on Vehicles with Tinted Glass! Available Online: http://www.mangalorean.com/news.php?newstype=broadcast\&broadcastid=450433 (accessed on 7 January 2014).

9. Impoundable Violations DOTC-LTO (MC 89-105). Metropolitan Manila Development Authority Website. Available online: http://www.mmda.gov.ph/faq.html\#page-16 (accessed on 23 April 2014).

10. Harrow, C.M. Public Utility Vehicles Told to Remove Tint. Available Online: http://www.sunstar.com.ph/davao/local-news/public-utility-vehicles-told-remove-tints (accessed on 4 January 2011).

11. Agence France-Presse. Tinted Windows Ban Upsets Russian Drivers. Available Online: http://news.ph.msn.com/weird-news/tinted-windows-ban-upsets-russian-drivers-2 (accessed on 10 July 2012).

12. Espulgar, W.; Santos, G.N. Characterization of silver (Ag) nanomaterials synthesized by the HVPCG technique. IJSER 2011, 2, 126-129.

13. Yang, L.; Mao, J.; Zhang, X.; Xue, T.; Hou, T.; Wang, L.; Mingjing, T.U. Preparation and characteristics of Ag/nano-ZnO composite antimicrobial agent. Nanosciences 2006, 1, 44-48.

14. Hajipour, M.J.; Fromm, K.M.; Ashkarran, A.A.; de Aberasturi, D.J.; de Larramendi, I.R.; Rojo, T.; Serpooshan, V.; Parak, W.J.; Mahmoudi, M. Antibacterial properties of nanoparticles. Trends Biotechnol. 2012, 30, 499-511.

15. Morones, J.R.; Elechiguerra, J.L.; Camacho, A.; Holt, K.; Kouri, J.B.; Ramirez, J.T.; Yacaman, M.J. The bactericidal effect of silver nanoparticles. Nanotechnology 2005, 16, doi:10.1088/0957-4484/ 16/10/059.

16. Application of Nanotechnology in Lacquer Top Coat-Laboratory Studies. Available Online: http://www.primjetcolor.com.pl/badania_naukowe_ns_eng.html (accessed on 23 April 2014).

17. Lu, H.; Fei, B.; Xin, J.H.; Wang, R.; Li, L. Fabrication of UV-blocking nanohybrid coating via miniemulsion polymerization. J. Colloid Interface Sci. 2006, 300, 111-116.

(C) 2014 by the authors; licensee MDPI, Basel, Switzerland. This article is an open access article distributed under the terms and conditions of the Creative Commons Attribution license (http://creativecommons.org/licenses/by/3.0/). 